\title{
Birth conditions affect the longevity of Holstein offspring
}

\author{
Gabriel M. Dallago, ${ }^{1 *} \odot$ Roger I. Cue, ${ }^{1}$ Kevin M. Wade, ${ }^{1} \odot$ René Lacroix, ${ }^{2} \odot$ and Elsa Vasseur ${ }^{1} \oplus$ \\ ${ }^{1}$ Department of Animal Science, McGill University, Sainte-Anne-de-Bellevue, Quebec H9X 3V9, Canada \\ ${ }^{2}$ Lactanet, Sainte-Anne-de-Bellevue, Quebec H9X 3R4, Canada
}

\section{ABSTRACT}

Studies of dairy cow longevity usually focus on the animal life after first calving, with few studies considering early life conditions and their effects on longevity. The objective was to evaluate the effect of birth conditions routinely collected by Dairy Herd Improvement agencies on offspring longevity measured as length of life and length of productive life. Lactanet provided 712,890 records on offspring born in 5,425 Quebec dairy herds between January 1999 and November 2015 for length of life, and 506,066 records on offspring born in 5,089 Quebec dairy herds between January 1999 and December 2013 for length of productive life. Offspring birth conditions used in this study were calving ease (unassisted, pull, surgery, or malpresentation), calf size (small, medium, or large), and twinning (yes or no). Observations were considered censored if the culling reason was "exported," "sold for dairy production," or "rented out" as well as if the animals were not yet culled at the time of data extraction. If offspring were not yet culled when the data were extracted, the last test-day date was considered the censoring date. Conditional inference survival trees were used in this study to analyze the effect of offspring birth conditions on offspring longevity. The hazard ratio of culling between the groups of offspring identified by the survival trees was estimated using a Cox proportional hazard model with herd-year-season as a frailty term. Five offspring groups were identified with different length of life based on their birth condition. Offspring with the highest length of life [median $=3.61$ year; median absolute deviation $(\mathrm{MAD})=1.86]$ were those classified as large or medium birth size and were also the result of an unassisted calving. Small offspring as a result of a twin birth had the lowest length of life (median $=2.20$ year; MAD $=1.69$ ) and were 1.52 times more likely to be culled early in life. Six groups were identified with different length of productive life. Offspring that resulted from an unassisted or surgery calving and classified as large

Received January 25, 2021.

Accepted October 2, 2021.

*Corresponding author: gabriel.dallago@mail.mcgill.ca or medium when they were born were in the group with the highest length of productive life (median $=2.03$ year; MAD $=1.63$ ). Offspring resulting from a malpresentation or pull in a twin birth were in the group with the lowest length of productive life (median $=1.15$ year; $\mathrm{MAD}=1.11$ ) and were 1.70 times more likely to be culled early in life. In conclusion, birth conditions of calving ease, calf size, and twinning greatly affected offspring longevity, and such information could be used for early selection of replacement candidates.

Key words: machine learning, survival tree, culling, precision dairy farming

\section{INTRODUCTION}

Dairy cow longevity is a complex functional trait that reflects the culling decisions made by a producer while taking into consideration many different aspects of the lifespan of a dairy animal (Van Doormaal, 2009). Cow longevity is associated with the overall sustainability of the dairy industry because short longevity is associated with financial losses on farms (Brickell and Wathes, 2011; Pellerin et al., 2014; Boulton et al., 2017), increased environmental footprint of milk production (Benbrook et al., 2010; Grandl et al., 2019), and impaired animal welfare status (Berry, 2015; De Vries, 2020). Even though the genetic potential for longevity has increased over time because the calculation of breeding values started to incorporate functional traits (De Vries, 2017; CRV, 2020; DairyNZ, 2020), the phenotypical expression of such potential has been identified as a problem requiring further research.

Longevity has been defined as an animal having an early first calving followed by a long productive life under profitable production levels (Dallago et al., 2021). Such definition was proposed because longevity is not only influenced by milk production, but also reproduction performance, incidence of health issues, and profitability (Compton et al., 2017; De Vries and Marcondes, 2020). Even though no metric exists covering all longevity facets outlined in the definition, length of life $(\mathbf{L L})$ and length of productive life $(\mathbf{L P L})$ are 2 of the most common (Dallago et al., 2021). Although the former accounts for the entire length of time an 
animal stays in the herd (i.e., from birth to culling or death; Haworth et al., 2008), the latter measures the length of time between first calving and culling or death (Ducrocq, 1994; Schneider et al., 2007; Haworth et al., 2008).

The study of dairy cow longevity usually begins only after the animal's first calving, mainly focusing on LPL, whereas less attention has been given to early life conditions. For instance, culling has been extensively studied within lactations. Culling at the beginning of the lactation is often related to the incidence of injuries and diseases (Pinedo et al., 2010, 2014), whereas culling later in lactation is associated with reproduction problems and low milk production (Pinedo et al., 2010, 2014; Heise et al., 2016).

Although studied to a much lesser extent, a few studies have indicated the existence of long-term effects of pre-partum and early life conditions that would affect cow longevity. Offspring born to dams exposed to heat stress during the dry period had a compromised passive immune transfer and weighed less both at birth and weaning (Tao et al., 2012; Monteiro et al., 2016); their survival and first-lactation milk production were also negatively affected (Monteiro et al., 2016). The occurrences of health problems before the first calving were reported to negatively affect milk production (Svensson and Hultgren, 2008) and reproduction (Hultgren and Svensson, 2010) of dairy cows. In addition, a high ADG from birth to weaning was associated with early age at first calving (Vacek et al., 2015), high milk yield in the first lactation (Svensson and Hultgren, 2008; Vacek et al., 2015), and low occurrence of veterinarian-treated cases of mastitis at the beginning of the lactation of primiparous cows (Svensson et al., 2006). Because failure to reproduce, incidence of health issues such as mastitis and feet and leg problems, and low milk production are the main reported reasons for culling in high milk-producing countries (Dallago et al., 2021), altogether these studies provide evidence that early life conditions - especially during the rearing period-have an adverse effect on cow longevity.

Therefore, it was hypothesized that birth conditions have an effect on offspring longevity, and the objective of this study was to evaluate that effect using birth condition variables routinely collected by DHI agencies.

\section{MATERIALS AND METHODS}

\section{Data Set}

A retrospective longitudinal study was conducted using DHI data from dairy herds in the province of Quebec, Canada, provided by the Canadian DHI agency Lactanet Inc. and organized into animal, lac- tation, and test-day data. The animal data contained animal identification variables [offspring identification (ID), offspring registration ID, dam registration ID, and sire registration ID], breed (offspring, dam, and sire), birth date, and left herd date of 3,380,326 records on offspring born in 7,660 Quebec dairy herds between September 1961 and December 2015. The lactation data had total lactation performance (i.e., milk, fat, and protein production), lactation start date, and birth conditions (calving ease, calf size, and twinning) of 4,698,162 records on offspring that calved in 7,521 Quebec dairy herds between September 1991 and December 2015. The test-day data contained offspring performance similar to the lactation data but from each individual test day $(\mathrm{n}=50,368,719$ records on offspring with a test day between January 2000 and December 2015 on 7,525 herds).

Birth conditions used in this study were calving ease (unassisted, pull, surgery, or malpresentation), calf size (small, medium, or large), and twinning (yes or no). Birth conditions were available in the lactation data file, but they were identified by the dam ID. Offspring ID, on the other hand, was available in the animal data, but associated with the dam registration ID. Therefore, to obtain a dam ID associated with the offspring ID, and to extract the birth conditions, we merged offspring registration ID with dam registration ID from the animal data $(\mathrm{n}=1,684,222$ records with no match and excluded). Duplicated observations on animal ( $\mathrm{n}=$ 248 records) and lactation ( $\mathrm{n}=232,823$ records) data files were excluded before both files were merged based on dam ID, year, and season of calving and birth. Next, records with missing observations on birth conditions were excluded ( $\mathrm{n}=88,240$ records excluded). After the merge, there remained 1,082,122 records from offspring that were born between April 1997 and December 2015. For all cases of duplicated records, both records were excluded. Recorded freemartins (i.e., twin to a bull) were removed. In addition, observations were removed where the sex of one of the twins was missing to avoid the possible effect of not recorded freemartins. The data were then filtered to contain only information about female Holstein offspring and a minimum of 3 observations per herd-year-season of birth. Figure 1 shows a flowchart of the data preparation procedures.

The LL and LPL were the longevity metrics evaluated in this study. The LL was calculated as the length of time (year) between birth and death (or culling) or censoring (Haworth et al., 2008), whereas the LPL was the length of time (year) between the first calving and death (or culling) or censoring (Ducrocq, 1994; Schneider et al., 2007). Time to event was defined as the time between birth and death (or culling) or censoring for LL and between first calving and death (or culling) 

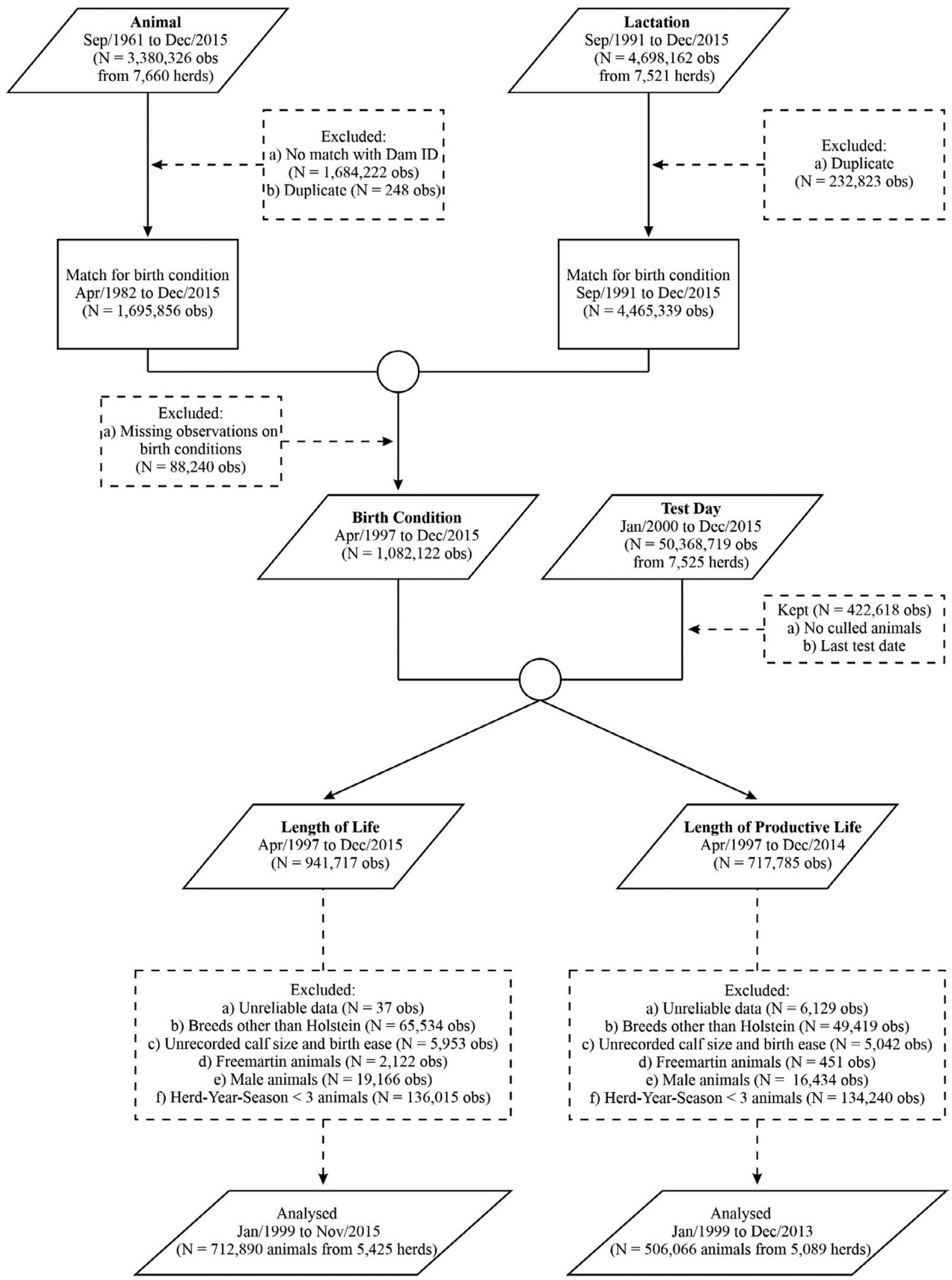

Figure 1. Flowchart of herds and animal selection. Parallelograms represent data input and output, solid-line rectangles represent intermediary steps, dashed-line rectangles represent processes, and circles represent the merging of files. Obs $=$ observations. 
Table 1. Descriptive statistics showing the prevalence of distinct birth conditions according to the different measures of longevity

\begin{tabular}{|c|c|c|c|c|}
\hline \multirow[b]{2}{*}{ Birth condition } & \multicolumn{2}{|c|}{$\begin{array}{l}\text { Length of life }^{1} \\
(\mathrm{n}=712,890)\end{array}$} & \multicolumn{2}{|c|}{$\begin{array}{l}\text { Length of productive life }{ }^{2} \\
\qquad(\mathrm{n}=506,066)\end{array}$} \\
\hline & $\mathrm{N}$ & $\%$ & $\mathrm{~N}$ & $\%$ \\
\hline \multicolumn{5}{|l|}{ Calving ease } \\
\hline Malpresentation & 10,068 & 1.41 & 7,110 & 1.40 \\
\hline Pull & 243,220 & 34.12 & 173,303 & 34.25 \\
\hline Surgery & 650 & 0.09 & 451 & 0.09 \\
\hline Unassisted & 458,952 & 64.38 & 325,202 & 64.26 \\
\hline \multicolumn{5}{|l|}{ Calf size } \\
\hline Large & 119,957 & 16.83 & 87,054 & 17.20 \\
\hline Medium & 492,852 & 69.13 & 351,607 & 69.48 \\
\hline Small & 100,081 & 14.04 & 67,405 & 13.32 \\
\hline \multicolumn{5}{|l|}{ Twinning } \\
\hline No & 701,928 & 98.46 & 499,440 & 98.69 \\
\hline Yes & 10,962 & 1.54 & 6,626 & 1.31 \\
\hline
\end{tabular}

${ }^{1}$ Length of time between birth and death or culling (Haworth et al., 2008).

${ }^{2}$ Length of time between the first calving and death or culling (Ducrocq, 1994; Schneider et al., 2007).

or censoring for LPL. An observation was considered censored if, at the time that the data were extracted from the DHI database, the offspring was not yet culled ( $\mathrm{n}=321,483$ for LL and $\mathrm{n}=240,792$ for LPL) or if the reported culling reason was "exported" ( $\mathrm{n}=25,297$ for LL and $\mathrm{n}=13,500$ for LPL), "sold for dairy production" ( $\mathrm{n}=49,087 \mathrm{LL}$ and $\mathrm{n}=34,517$ for LPL), or "rented out" ( $\mathrm{n}=1,496$ for LL and $\mathrm{n}=1,203$ for LPL). If the offspring were not yet culled when the data were extracted, the last test-day date was considered as the censoring date. For the other cases, offspring were considered censored at the date of the reported removal.

After the data handling and cleaning, there remained data from 712,890 female Holstein offspring born between January 1999 and November 2015 in 5,425 herds for LL and from 506,066 female Holstein offspring born between January 1999 and December 2013 in 5,089 herds for LPL.

\section{Data Analysis}

All statistical analyses were carried out using $R$ version 4.0.2 (https://www.r-project.org/) and its packages as follows: coxme (Therneau, 2020a), partykit (Hothorn et al., 2006; Hothorn and Zeileis, 2015), survival (Therneau, 2020b), and survminer (Kassambara et al., 2020). The statistical significance level was set at $\alpha<0.05$.

Similar to Probo et al. (2018), conditional inference survival trees were used in this study to analyze the effect of birth conditions on offspring longevity because it has been shown to be less prone to overfitting and more reliable than other survival tree algorithms (Zhou and McArdle, 2015). In short, this algorithm aims at recursively partitioning the data into different nodes (i.e., group of offspring) based on the response variable.
At each step, it selects independent variables with the highest ability to split the observations of offspring with different longevity. Therefore, the earlier a variable is used to split the data and originate a node, the higher its ability is to identify offspring with different longevity. This is repeated until the independence hypothesis between the response and any of the independent variables cannot be rejected (Hothorn et al., 2006). By doing so, the algorithm is able to automatically group offspring separately within the LL and LPL and the independent variables under consideration as well as detecting high-level interactions without the need to specify them (Ramezankhani et al., 2017). The trees were created having LL and LPL individually as the response variable and using the ctree function (Hothorn et al., 2006). The resulting groups of offspring identified by the survival tree were used as a categorical variable to estimate the hazard ratio (HR) of culling using a shared frailty Cox proportional hazard model. A frailty term for the combined effect of the herd-year-season of birth (HYS) of the offspring [HYS $\sim \mathrm{N}\left(0, \sigma^{2}\right)$ ] was included in the model to account for the shared frailty between offspring within the same HYS. The offspring longevity was assumed to be independent, conditional on the HYS. The group with the lowest culling risk (i.e., highest longevity) was used as the reference level. In addition, Kaplan-Meier curves were constructed for each of the groups.

\section{RESULTS}

Among studied offspring, 321,483 (45.1\%) and 240,792 (47.6\%) were censored for LL and LPL, respectively. Among offspring that were not censored, the overall median LL was 3.53 yr [median absolute 
deviation $(\mathbf{M A D})=1.82 ; 95 \%$ percentile compatibility interval $(\mathbf{P C I})=3.53-3.54]$, and the overall median LPL was 1.98 yr $(\mathrm{MAD}=1.62 ; 95 \% \mathrm{PCI}=1.97-1.99)$. Descriptive statistics for the offspring birth conditions are presented in Table 1.

\section{Length of Life}

All 3 offspring birth conditions evaluated in this study were selected by the survival tree algorithm to group the offspring (Supplemental Figure S1, https: //escholarship.mcgill.ca/concern/articles/vq27zt02t ?locale $=\mathrm{en})$. Calf size was found as the most important condition because it was at the top of the tree. Five groups were identified with different offspring LL based on their birth condition $(P<0.001$; Supplemental Figure S1). Offspring with the highest LL were those that were classified as large or medium size at birth and were the result of an unassisted calving (node 6; Supplemental Figure S1), whereas offspring that were a small size at birth as a result of a twin birth (node 9; Supplemental Figure S1) were in the group with the lowest LL (Table 2). Therefore, the HR of culling was the highest for node 9 (Table 2), with node 6 as the reference group (Table 2). The Kaplan-Meier curves for these groups are shown in Figure 2A, where the curve for node 6 was the only one higher than the overall average curve, indicating that it covered a low-risk group for culling events.

\section{Length of Productive Life}

Similar to LL, all 3 offspring birth conditions evaluated in this study were also selected by the survival tree algorithm to group the offspring based on LPL
(Supplemental Figure S2, https://escholarship.mcgill .ca/concern/articles/vq27zt02t?locale=en). However, calving ease was found as the most important condition in this case, and 6 groups were identified with different LPL $(P<0.001$; Supplemental Figure S2). Offspring that resulted from an unassisted or surgery calving and were classified as large or medium size at birth (node 8; Supplemental Figure S2) were in the group with the highest LPL, whereas offspring resulting from a malpresentation or pull in a twin birth (node 6; Supplemental Figure S2) were in the group with the lowest LPL (Table 3). Accordingly, the HR of culling was the highest for node 6 , with node 8 as the reference group (Table 3). The Kaplan-Meier curves for these groups are shown in Figure 2B, where the curve for node 8 was also the only one higher than the overall average curve, indicating that it covered a low-risk group for culling events.

\section{DISCUSSION}

Different indicators of birth condition were selected by the machine-learning algorithm to first split the observations into groups of offspring with different LL (Supplemental Figure S1) and LPL (Supplemental Figure S2). The first split contains the indicator with the strongest association with the response variable (Hothorn et al., 2006). The results of our study indicated that size at birth is the birth condition with the strongest association with the LL (Supplemental Figure S1). Because the main difference between LL and LPL is the inclusion of the length of the nonproductive life stage of the animal in the former, our results suggested that size at birth had the strongest association with the ability of the offspring to avoid herd removal up to

Table 2. Descriptive statistics and hazard ratio of the patterns identified by the conditional inference survival tree for the length of life

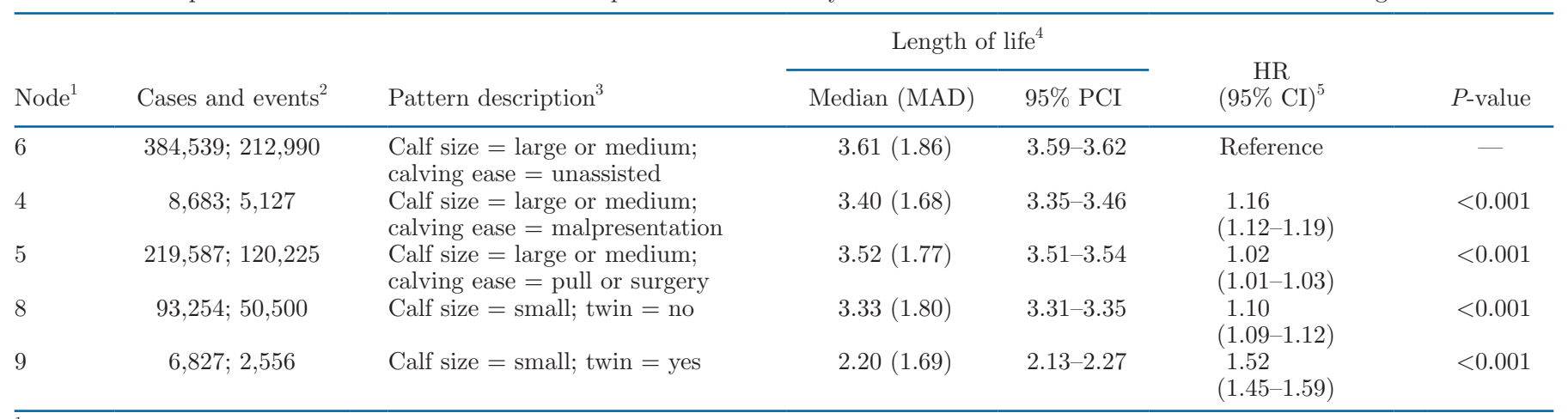

\footnotetext{
${ }^{1}$ Terminal node identified by the survival tree algorithm for the length of life.

${ }^{2}$ Cases $=$ Number of offspring in each node; events = number of offspring in each node with an observed culling event.

${ }^{3}$ Simplified pattern description of each terminal node.

${ }^{4}$ Median (median absolute deviation; MAD) and 95\% percentile compatibility interval (PCI; Greenland, 2019).

${ }^{5} \mathrm{HR}(95 \% \mathrm{CI})=$ hazard ratio and 95\% compatibility interval (Greenland, 2019).
} 

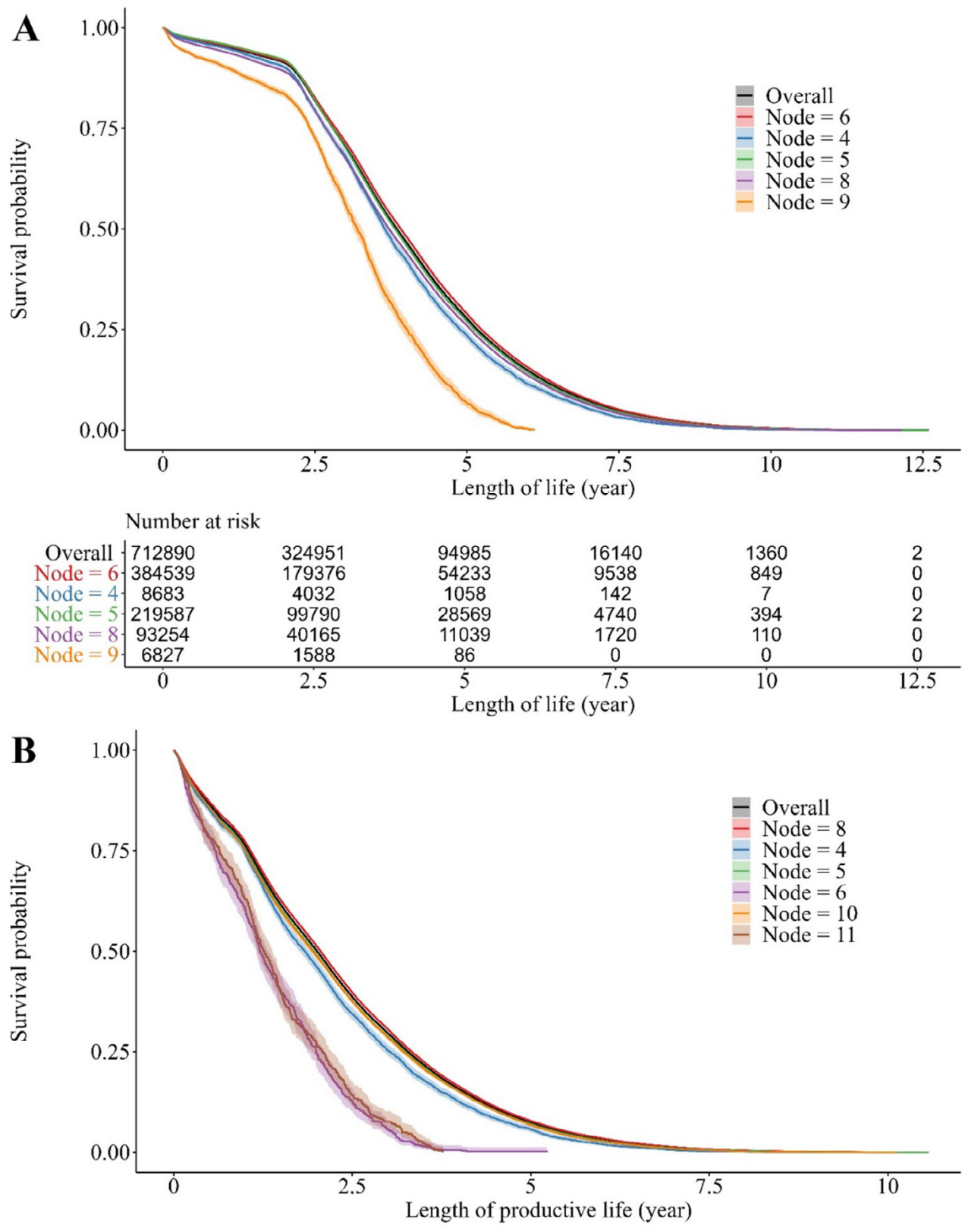

Number at risk

\begin{tabular}{|c|c|c|c|c|c|}
\hline $\begin{array}{c}\text { Overall } \\
\text { Node }=8 \\
\text { Node }=4 \\
\text { Node }=5 \\
\text { Node }=6 \\
\text { Node }=10 \\
\text { Node }=11\end{array}$ & $\begin{array}{c}506066 \\
275535 \\
6853 \\
170865 \\
2695 \\
47577 \\
2541 \\
\end{array}$ & $\begin{array}{c}101065 \\
57795 \\
1307 \\
33122 \\
70 \\
8696 \\
75 \\
\end{array}$ & $\begin{array}{c}19316 \\
11358 \\
216 \\
6171 \\
1 \\
1570 \\
0 \\
\end{array}$ & $\begin{array}{c}1743 \\
1099 \\
10 \\
523 \\
0 \\
111 \\
0 \\
\end{array}$ & $\begin{array}{l}12 \\
6 \\
0 \\
5 \\
0 \\
1 \\
0 \\
\end{array}$ \\
\hline & $\dot{0}$ & 2.5 & 5 & 7.5 & 10 \\
\hline
\end{tabular}

Figure 2. The Kaplan-Meier survival curves, followed by the $95 \%$ compatibility interval (Greenland, 2019), of the terminal nodes identified by the survival tree algorithm for the length of life (A) and the length of productive life (B). The risk table at the bottom of both plots indicates the number of offspring at risk of being culled at different times. In both plots, the solid black line (overall) shows the survival curve of the total population, and the other lines show the survival curve of each terminal node. The terminal nodes of graph A represent the following patterns: node $=6$ : large or medium calf size and unassisted calving ease; node $=4$ : large or medium calf size and malpresentation calving ease; node $=5$ : large or medium calf size and pull or surgery calving ease; node $=8$ : small calf size and no twinning; node $=9$ : small calf size and twinning. The terminal nodes of graph B represent the following patterns: Node $=8$ : surgery or unassisted calving ease and large or medium calf size; node $=4$ : malpresentation calving ease and no twin birth; node $=5$ : pull calving ease and no twin birth; node $=6$ : malpresentation or pull calving ease and twining; node $=10$ : surgery or unassisted calving ease, small calf size, and no twinning; node $=11$ : surgery or unassisted calving ease, small calf size, and twinning. 
Table 3. Descriptive statistics and hazard ratio of the patterns identified by the conditional inference survival tree for the length of productive life

\begin{tabular}{|c|c|c|c|c|c|c|}
\hline Node $^{1}$ & Cases and events ${ }^{2}$ & Pattern description ${ }^{3}$ & \multicolumn{2}{|c|}{ Length of productive life ${ }^{4}$} & $\begin{array}{c}\mathrm{HR} \\
(95 \% \mathrm{CI})^{5}\end{array}$ & $P$-value \\
\hline 8 & 275,$535 ; 147,301$ & $\begin{array}{l}\text { Calving ease = surgery or unassisted; } \\
\text { calf size = large or medium }\end{array}$ & $2.03(1.63)$ & $2.02-2.04$ & Reference & - \\
\hline 4 & 6,$853 ; 3,859$ & $\begin{array}{l}\text { Calving ease = malpresentation; } \\
\text { twin = no }\end{array}$ & $1.80(1.49)$ & $1.72-1.87$ & $\begin{array}{l}1.15 \\
(1.11-1.20)\end{array}$ & $<0.001$ \\
\hline 5 & 170,$865 ; 89,410$ & $\begin{array}{l}\text { Calving ease = pull; } \\
\text { twin }=\text { no }\end{array}$ & $1.93(1.62)$ & $1.92-1.94$ & $\begin{array}{l}1.05 \\
(1.04-1.06)\end{array}$ & $<0.001$ \\
\hline 10 & 47,$577 ; 23,552$ & $\begin{array}{l}\text { Calving ease = surgery or unassisted; } \\
\text { calf size = small; twin }=\text { no }\end{array}$ & $1.91(1.62)$ & $1.88-1.94$ & $\begin{array}{l}1.05 \\
(1.04-1.07)\end{array}$ & $<0.001$ \\
\hline 11 & 2,$541 ; 562$ & $\begin{array}{l}\text { Calving ease = surgery or unassisted; } \\
\text { calf size = small; twin = yes }\end{array}$ & $1.18(1.15)$ & $1.10-1.28$ & $\begin{array}{l}1.63 \\
(1.48-1.79)\end{array}$ & $<0.001$ \\
\hline
\end{tabular}

\footnotetext{
${ }^{1}$ Terminal node identified by the survival tree algorithm for the length of productive life.

${ }^{2}$ Cases $=$ number of offspring in each node; events $=$ number of offspring in each node with an observed culling event.

${ }^{3}$ Simplified pattern description of each terminal node.

${ }^{4}$ Median (median absolute deviation; MAD) and 95\% percentile compatibility interval (PCI; Greenland, 2019).

${ }^{5} \mathrm{HR}(95 \% \mathrm{CI})=$ hazard ratio and $95 \%$ compatibility interval (Greenland, 2019).
}

the first calving. In turn, this would be influenced by the mortality rate because it is higher during the early life stages compared with lactating cows (Compton et al., 2017).

Calf weight at birth, as a proxy for calf size, has been reported to be associated with calf mortality. For instance, clinically normal calves that died at birth or within $24 \mathrm{~h}$ after birth were, on average, $6 \mathrm{~kg}$ lighter than calves that died due to difficult calving (Berglund et al., 2003), which could be because smaller calves would have an undeveloped immune system and low body energy reserve, making them more susceptible to hypothermia (Wathes et al., 2008). The growth of small calves is also compromised, which negatively influences the age at first calving and the ability to remain in the herd. Body weight gain is positively associated with birth weight, in which the higher the birth weight, the higher the $\mathrm{BW}$ is at 6,9 , and 15 mo old (Swali and Wathes, 2006). Brickell et al. (2007) reported that cows with a higher BW at 6 mo old (183 $\mathrm{kg} ; \mathrm{SD}=36 \mathrm{~kg}$ ) had an age at first calving lower than 23 mo compared with animals with a lower BW at at 6 mo old $(162 \mathrm{~kg} ; \mathrm{SD}=35 \mathrm{~kg})$. Additionally, a positive relationship was reported between first-lactation milk yield and the ADG from weaning to first service (Svensson and Hultgren, 2008) or conception (Vacek et al., 2015) as well as between the ADG during the first 2 mo of life and completing the first lactation (Bach, 2011).

Although the same size at birth, calves with difficult calving had a higher HR of being culled compared with offspring with an unassisted birth for both LL (Table 2) and LPL (Table 3). In addition to increasing the risk of stillbirths (Berglund et al., 2003; Lombard et al., 2007) and mortality during the first $21 \mathrm{~d}$ of life (Wells et al., 1996), difficult calving has been associated with failure of passive-immunity transfer (Renaud et al., 2020) and with low calf vitality (Barrier et al., 2012). Difficult calving also increases the risk of developing respiratory and digestive diseases between birth and $120 \mathrm{~d}$ of age (Lombard et al., 2007). The negative consequences of a difficult calving are likely to have long-term effects. Difficult calving was associated with increased age at first calving (Heinrichs et al., 2005), which in turn makes animals less likely to complete a first lactation (Bach, 2011; Sherwin et al., 2016). In addition, difficult calving was associated with a reduction in cumulative milk yield in the first lactation of the offspring (Eaglen et al., 2011), which would increase the chances of early culling.

Even though results from this study indicated that calving assistance has negative effects on offspring longevity, delivery assistance alone is not likely to be a problem. Systematically assisting the delivery of calves that do not present clear signs of dystocia improves the calf vigor and does not influence the likelihood of stillbirth (Villettaz Robichaud et al., 2017a) as well as the occurrence of pneumonia, diarrhea, and the survival of the offspring up to weaning at 7 wk old (Villettaz Robichaud et al., 2017b). Even though further studies are needed to evaluate the long-term effects of systematically assisting the delivery on offspring longevity, this would indicate that calving assistance as a consequence of dystocia would have a negative effect on offspring 
longevity because this is likely the most prevalent scenario in our study given the rate of assistance provided by Canadian farmers (Villettaz Robichaud et al., 2016).

The occurrence of twinning had a negative effect on offspring longevity measured as LL (Table 2 and Supplemental Figure S1) or LPL (Table 3 and Supplemental Figure S2). The overall twinning rate in dairy cows was estimated to be $4.2 \%$ in the United States, but it increased with the parity of the dam as well as overtime between 1996 and 2004 (Silva del Río et al., 2007). This overall prevalence was higher than the values reported here (Table 1), most likely because freemartins were removed from our study. The negative consequences of twining on the dam's survival are well documented. For example, it increases the HR of multiparous cows being culled within 120 DIM (Probo et al., 2018). However, twining has also been reported to have negative consequences on the offspring. The occurrence of twin births was identified as a mortality risk factor within the first $24 \mathrm{~h}$ after birth (Lombard et al., 2007; Silva del Río et al., 2007) as well as up to $21 \mathrm{~d}$ of life (Wells et al., 1996). Twining is also associated with low BW (Windeyer et al., 2014) and ADG (Shivley et al., 2018) compared with single births. Such consequences are likely to have a cascade effect that compromises the ability of the offspring to remain in the herd, resulting in reduced offspring longevity as suggested by the results in this study.

The overall average longevity observed in the present study was low but in agreement with results published previously. Hertl et al. (2018) reported similar results with an average LPL of approximately $2 \mathrm{yr}$, based on 24,831 Holstein cows from 5 herds in New York State, whereas Hultgren and Svensson (2009) reported a median length of productive life of $2.1 \mathrm{yr}$ among 2,124 culled dairy cows from 109 Swedish herds. On the other hand, the genetic potential for longevity has increased over time because the calculation of breeding values started to incorporate functional traits (De Vries, 2017; CRV, 2020; DairyNZ, 2020). Based on a combination of survival data and various nonproduction traits known to be associated with longevity (Beavers and Van Doormaal, 2017), the genetic potential for LL of the average Canadian Holstein cow born in 2018, for example, was estimated to be of $8.5 \mathrm{yr}$ (Lactanet, 2021). This would represent an LPL of $6.3 \mathrm{yr}$ if an average age at first calving of $27 \mathrm{mo}$ is assumed. However, the culling rate in Canada was $32.36 \%$ in 2020 among herds enrolled in a milk recording program (CDIC, 2021). This represents an LPL of $3.09 \mathrm{yr}$, which is about half of the genetic potential of the cows. Results from the above literature indicate that dairy cows are not expressing their full potential for longevity, and the present study provided insights on the adverse effect of birth conditions (i.e., calving ease, birth size, and twinning) on offspring longevity, which could be used in replacement and culling strategies to select the best candidates for early herd removal.

Early life indicators of longevity are required to support farmers' culling and replacement strategies. Age at first calving has been proposed as an indicator of longevity because animals that calve for the first time at a younger age are less likely to be culled (Bach, 2011; Sherwin et al., 2016) and more likely to have a long productive life (Hultgren and Svensson, 2009). However, much earlier indicators would be desirable because age at first calving only happens at approximately 2 yr after birth. The results of the present study indicated that birth conditions could be used as early indicators of offspring longevity by identifying offspring during the rearing period that are less likely to express their maximum potential, which could support farmers in the early selection of replacement animals.

The present study focused on indicators of birth conditions that are available in DHI databases. Our results are likely to be influenced by the fact that $26.7 \%$ of Canadian farmers always assist their cows during calving, and $38 \%$ always assist all heifers regardless of the necessity to do so (Villettaz Robichaud et al., 2016). In addition, a limitation of our approach is the inherited subjectivity of the records reported by dairy farmers. For instance, classifying calf size into small, medium, and large is, to some extent, subjective to the farmer's criteria, which is likely to vary among different farmers. Even though a certain standardization is present, some heterogeneity is present in the way people apply these standards due to their perceptions. Our results provided a strong incentive for farmers to record actual weight at birth, making birth-size information more precise given its potential to help identify offspring that may stay longer in the herd and optimize replacement and culling strategies.

\section{CONCLUSIONS}

Our results indicated the existence of a long-term effect of birth conditions on offspring longevity. Calving ease, birth size, and twinning are associated with a reduction in both LL and LPL and affect the ability of the offspring to remain in the herd. This information provides insights to optimize replacement and culling strategies in dairy herds and to propose early indicators for the selection of the best candidates for early herd removal. 


\section{ACKNOWLEDGMENTS}

The authors acknowledge the funding support provided by Novalait (Quebec City, Canada), Dairy Farmers of Canada (Ottawa, Canada), Valacta (now Lactanet; Sainte-Anne-de-Bellevue, Canada), and Natural Sciences and Engineering Research Council (NSERC; Ottawa, Canada) as part of Industrial Research Chair in the Sustainable Life of Dairy Cattle (Chairholder: E.V., IRCPJ 492639 - 15). The authors also acknowledge the program CREATE in Milk Quality of NSERC, the Op+lait group of the Fonds de Recherche du Québec - Nature et Technologies (FRQNT; Saint-Hyacinthe, Canada), and McGill University (Sainte-Anne-deBellevue, Canada), through the Pilarczyk Fellowship and Graduate Excellence Awards, for providing stipend funding to G. M. D. The authors have not stated any conflicts of interest.

\section{REFERENCES}

Bach, A. 2011. Associations between several aspects of heifer development and dairy cow survivability to second lactation. J. Dairy Sci. 94:1052-1057. https://doi.org/10.3168/jds.2010-3633.

Barrier, A. C., E. Ruelle, M. J. Haskell, and C. M. Dwyer. 2012. Effect of a difficult calving on the vigour of the calf, the onset of maternal behaviour, and some behavioural indicators of pain in the dam. Prev. Vet. Med. 103:248-256. https://doi.org/10.1016/j .prevetmed.2011.09.001.

Beavers, L., and B. Van Doormaal. 2017. Herd life and voluntary disposals. Accessed Sep. 23, 2021. https://www.cdn.ca/document .php?id=467.

Benbrook, C., C. Carman, E. A. Clark, C. Daley, W. Fulwider, M. Hansen, C. Leifert, K. Martens, L. Paine, L. Petkewitz, G. Jodarski, F. Thicke, J. Velez, and G. Wegner. 2010. A dairy farm's footprint: Evaluating the impacts of conventional and organic farming systems. Critical Issue Report. The Organic Center.

Berglund, B., L. Steinbock, and M. Elvander. 2003. Causes of stillbirth and time of death in Swedish Holstein calves examined post mortem. Acta Vet. Scand. 44:111-120. https://doi.org/10.1186/ 1751-0147-44-111.

Berry, D. P. 2015. Breeding the dairy cow of the future: What do we need? Anim. Prod. Sci. 55:823-837. https://doi.org/10.1071/ AN14835.

Boulton, A. C., J. Rushton, and D. C. Wathes. 2017. An empirical analysis of the cost of rearing dairy heifers from birth to first calving and the time taken to repay these costs. Animal 11:1372-1380. https://doi.org/10.1017/S1751731117000064.

Brickell, J. S., N. Bourne, Z. Cheng, and D. C. Wathes. 2007. Influence of plasma IGF-I oncentrations and body weight at 6 months on age at first calving in dairy heifers on commercial farms. Reprod. Domest. Anim. 42:118-119 (Abstract). https://doi.org/10.1111/j .1439-0531.2007.00910.x.

Brickell, J. S., and D. C. Wathes. 2011. A descriptive study of the survival of Holstein-Friesian heifers through to third calving on English dairy farms. J. Dairy Sci. 94:1831-1838. https://doi.org/ 10.3168/jds.2010-3710.

CDIC (Canadian Dairy Information Centre). 2021. Culling and replacement rates in dairy herds in Canada. Accessed Jul. 07, 2021. https://agriculture.canada.ca/en/canadas-agriculture -sectors/animal-industry/canadian-dairy-information-centre/dairy -statistics-and-market-information/dairy-animal-genetics/culling -and-replacement-rates-dairy-herds-canada.
Compton, C. W. R., C. Heuer, P. T. Thomsen, T. E. Carpenter, C. V. C. Phyn, and S. McDougall. 2017. Invited review: A systematic literature review and meta-analysis of mortality and culling in dairy cattle. J. Dairy Sci. 100:1-16. https://doi.org/10.3168/jds .2016-11302

CRV (Coöperatie Koninklijke CRV). 2020. Jaarstatistieken 2019 voor Nederland [Annual statistics 2019 for the Netherlands]. Arnhem, Netherlands. Accessed Apr. 20, 2020. https://cooperatiecrv-be6 .kxcdn.com/wp-content/uploads/2020/02/Jaarstatistieken-2019 -NL-totaal.pdf.

DairyNZ. 2020. Animal evaluation: Animal and herd averages. Accessed May 29, 2020. https://www.dairynz.co.nz/animal/animal -evaluation/animal-and-herd-averages.

Dallago, G. M., K. M. Wade, R. I. Cue, J. T. McClure, R. Lacroix, D. Pellerin, and E. Vasseur. 2021. Keeping dairy cows for longer: A critical literature review on dairy cow longevity in high milkproducing countries. Animals (Basel) 11:808. https://doi.org/10 $.3390 /$ ani11030808.

De Vries, A. 2017. Economic trade-offs between genetic improvement and longevity in dairy cattle. J. Dairy Sci. 100:4184-4192. https:/ /doi.org/10.3168/jds.2016-11847.

De Vries, A. 2020. Symposium review: Why revisit dairy cattle productive lifespan? J. Dairy Sci. 103:3838-3845. https://doi.org/10 $.3168 / j d s .2019-17361$.

De Vries, A., and M. I. Marcondes. 2020. Review: Overview of factors affecting productive lifespan of dairy cows. Animal 14:s155-s164. https://doi.org/10.1017/S1751731119003264.

Ducrocq, V. 1994. Statistical analysis of length of productive life for dairy cows of the Normande breed. J. Dairy Sci. 77:855-866. https: //doi.org/10.3168/jds.S0022-0302(94)77020-X.

Eaglen, S. A. E., M. P. Coffey, J. A. Woolliams, R. Mrode, and E. Wall. 2011. Phenotypic effects of calving ease on the subsequent fertility and milk production of dam and calf in UK Holstein-Friesian heifers. J. Dairy Sci. 94:5413-5423. https://doi.org/10.3168/ jds.2010-4040.

Grandl, F., M. Furger, M. Kreuzer, and M. Zehetmeier. 2019. Impact of longevity on greenhouse gas emissions and profitability of individual dairy cows analysed with different system boundaries. Animal 13:198-208. https://doi.org/10.1017/S175173111800112X.

Greenland, S. 2019. Valid P-values behave exactly as they should: Some misleading criticisms of $P$-values and their resolution with svalues. Am. Stat. 73(Suppl. 1):106-114. https://doi.org/10.1080/ 00031305.2018 .1529625$.

Haworth, G. M., W. P. Tranter, J. N. Chuck, Z. Cheng, and D. C. Wathes. 2008. Relationships between age at first calving and first lactation milk yield, and lifetime productivity and longevity in dairy cows. Vet. Rec. 162:643-647. https://doi.org/10.1136/vr.162 .20 .643 .

Heinrichs, A. J., B. S. Heinrichs, O. Harel, G. W. Rogers, and N. T. Place. 2005. A prospective study of calf factors affecting age, body size, and body condition score at first calving of Holstein dairy heifers. J. Dairy Sci. 88:2828-2835. https://doi.org/10.3168/jds .S0022-0302(05)72963-5.

Heise, J., Z. Liu, K. F. Stock, S. Rensing, F. Reinhardt, and H. Simianer. 2016. The genetic structure of longevity in dairy cows. J. Dairy Sci. 99:1253-1265. https://doi.org/10.3168/jds.2015-10163.

Hertl, J. A., Y. H. Schukken, L. W. Tauer, F. L. Welcome, and Y. T. Gröhn. 2018. Does clinical mastitis in the first 100 days of lactation 1 predict increased mastitis occurrence and shorter herd life in dairy cows? J. Dairy Sci. 101:2309-2323. https://doi.org/10.3168/ jds.2017-12615.

Hothorn, T., K. Hornik, and A. Zeileis. 2006. Unbiased recursive partitioning: A conditional inference framework. J. Comput. Graph. Stat. 15:651-674. https://doi.org/10.1198/106186006X133933.

Hothorn, T., and A. Zeileis. 2015. partykit: A modular toolkit for recursive partitioning in R. J. Mach. Learn. Res. 16:3905-3909.

Hultgren, J., and C. Svensson. 2009. Heifer rearing conditions affect length of productive life in Swedish dairy cows. Prev. Vet. Med. 89:255-264. https://doi.org/10.1016/j.prevetmed.2009.02.012. 
Hultgren, J., and C. Svensson. 2010. Calving interval in dairy cows in relation to heifer rearing conditions in southwest Sweden. Reprod. Domest. Anim. 45:136-141. https://doi.org/10.1111/j.1439-0531 2008.01273.x.

Kassambara, A., M. Kosinski, and P. Biecek. 2020. survminer: Drawing survival curves using 'ggplot2'. Version 0.4.8. Accessed Dec. 16, 2020. https://CRAN.R-project.org/package=survminer.

Lactanet. 2021. National genetic trends by birth year for Holstein cows. Accessed Sep. 23, 2021. https://www.cdn.ca/files_ge_articles.php.

Lombard, J. E., F. B. Garry, S. M. Tomlinson, and L. P. Garber. 2007. Impacts of dystocia on health and survival of dairy calves. J. Dairy Sci. 90:1751-1760. https://doi.org/10.3168/jds.2006-295.

Monteiro, A. P. A., S. Tao, I. M. T. Thompson, and G. E. Dahl 2016. In utero heat stress decreases calf survival and performance through the first lactation. J. Dairy Sci. 99:8443-8450. https://doi .org/10.3168/jds.2016-11072.

Pellerin, D., S. Adams, F. Bécotte, R. Cue, R. Moore, and R. Roy. 2014. Pour une vache, l'âge d'or c'est la 4e lactation! [For a cow, the golden age is the fourth lactation!] Pages 133-147 in Proc. Symposium sur les bovins laitiers: Choix d'aujourd'hui pour les défis de demain. CRAAQ - Le Centre de référence en agriculture et agroalimentaire du Québec.

Pinedo, P. J., A. Daniels, J. Shumaker, and A. De Vries. 2014. Dynamics of culling for Jersey, Holstein, and Jersey $\times$ Holstein crossbred cows in large multibreed dairy herds. J. Dairy Sci. 97:2886-2895. https://doi.org/10.3168/jds.2013-7685.

Pinedo, P. J., A. De Vries, and D. W. Webb. 2010. Dynamics of culling risk with disposal codes reported by Dairy Herd Improvement dairy herds. J. Dairy Sci. 93:2250-2261. https://doi.org/10.3168/ jds.2009-2572.

Probo, M., O. B. Pascottini, S. LeBlanc, G. Opsomer, and M. Hostens. 2018. Association between metabolic diseases and the culling risk of high-yielding dairy cows in a transition management facility using survival and decision tree analysis. J. Dairy Sci. 101:94199429. https://doi.org/10.3168/jds.2018-14422.

Ramezankhani, A., M. Tohidi, F. Azizi, and F. Hadaegh. 2017. Application of survival tree analysis for exploration of potential interactions between predictors of incident chronic kidney disease: A 15-year follow-up study. J. Transl. Med. 15:240. https://doi.org/ 10.1186/s12967-017-1346-x.

Renaud, D. L., K. M. Waalderbos, L. Beavers, T. F. Duffield, K. E. Leslie, and M. C. Windeyer. 2020. Risk factors associated with failed transfer of passive immunity in male and female dairy calves: A 2008 retrospective cross-sectional study. J. Dairy Sci. 103:35213528. https://doi.org/10.3168/jds.2019-17397.

Schneider, M. P., E. Strandberg, U. Emanuelson, K. Grandinson, and A. Roth. 2007. The effect of veterinary-treated clinical mastitis and pregnancy status on culling in Swedish dairy cows. Prev. Vet. Med. 80:179-192. https://doi.org/10.1016/j.prevetmed.2007.02 .006 .

Sherwin, V. E., C. D. Hudson, A. Henderson, and M. J. Green. 2016. The association between age at first calving and survival of first lactation heifers within dairy herds. Animal 10:1877-1882. https:/ /doi.org/10.1017/S1751731116000689.

Shivley, C. B., J. E. Lombard, N. J. Urie, C. A. Kopral, M. Santin, T. J. Earleywine, J. D. Olson, and F. B. Garry. 2018. Preweaned heifer management on US dairy operations: Part VI. Factors associated with average daily gain in preweaned dairy heifer calves. J. Dairy Sci. 101:9245-9258. https://doi.org/10.3168/jds.2017-14022.

Silva del Río, N., S. Stewart, P. Rapnicki, Y. M. Chang, and P. M. Fricke. 2007. An observational analysis of twin births, calf sex ratio, and calf mortality in Holstein dairy cattle. J. Dairy Sci. 90:1255-1264. https://doi.org/10.3168/jds.S0022-0302(07)71614 -4 .

Svensson, C., and J. Hultgren. 2008. Associations between housing, management, and morbidity during rearing and subsequent firstlactation milk production of dairy cows in southwest Sweden. J. Dairy Sci. 91:1510-1518. https://doi.org/10.3168/jds.2007-0235.
Svensson, C., A. K. Nyman, K. P. Waller, and U. Emanuelson. 2006. Effects of housing, management, and health of dairy heifers on first-lactation udder health in southwest Sweden. J. Dairy Sci. 89:1990-1999. https://doi.org/10.3168/jds.S0022-0302(06)72266 -4 .

Swali, A., and D. C. Wathes. 2006. Influence of the dam and sire on size at birth and subsequent growth, milk production and fertility in dairy heifers. Theriogenology 66:1173-1184. https://doi.org/10 .1016/j.theriogenology.2006.03.028.

Tao, S., A. P. A. Monteiro, I. M. Thompson, M. J. Hayen, and G. E. Dahl. 2012. Effect of late-gestation maternal heat stress on growth and immune function of dairy calves. J. Dairy Sci. 95:7128-7136. https://doi.org/10.3168/jds.2012-5697.

Therneau, T. M. 2020a. coxme: Mixed effects Cox models. Version 2.216. Accessed Dec. 16, 2020. https://CRAN.R-project.org/package $=$ coxme.

Therneau, T. M. 2020b. survival: A package for survival analysis in R. Version 3.1-12. Accessed Dec. 16, 2020. https://CRAN.R-project .org $/$ package $=$ survival.

Vacek, M., L. Krpálková, J. Syrůček, M. Štípková, and M. Janecká. 2015. Relationships between growth and body condition development during the rearing period and performance in the first three lactations in Holstein cows. Czech J. Anim. Sci. 60:417-425. https: //doi.org/10.17221/8460-CJAS.

Van Doormaal, B. 2009. A closer look at longevity. Accessed Oct. 28 , 2020. https://www.cdn.ca/document.php?id=162.

Villettaz Robichaud, M., A. M. de Passillé, D. L. Pearl, S. J. LeBlanc, S. M. Godden, D. Pellerin, E. Vasseur, J. Rushen, and D. B. Haley. 2016. Calving management practices on Canadian dairy farms: Prevalence of practices. J. Dairy Sci. 99:2391-2404. https://doi .org/10.3168/jds.2015-9641.

Villettaz Robichaud, M., D. L. Pearl, S. M. Godden, S. J. LeBlanc, and D. B. Haley. 2017a. Systematic early obstetrical assistance at calving: I. Effects on dairy calf stillbirth, vigor, and passive immunity transfer. J. Dairy Sci. 100:691-702. https://doi.org/10 .3168/jds.2016-11213.

Villettaz Robichaud, M., D. L. Pearl, S. M. Godden, J. Rushen, S. J. LeBlanc, and D. B. Haley. 2017b. Systematic early obstetrical assistance at calving: II. Effects on dairy heifer calf growth, health, and survival to weaning. J. Dairy Sci. 100:703-712. https://doi .org/10.3168/jds.2016-11214.

Wathes, D. C., J. S. Brickell, N. E. Bourne, A. Swali, and Z. Cheng. 2008. Factors influencing heifer survival and fertility on commercial dairy farms. Animal 2:1135-1143. https://doi.org/10.1017/ S1751731108002322.

Wells, S. J., D. A. Dargatz, and S. L. Ott. 1996. Factors associated with mortality to 21 days of life in dairy heifers in the United States. Prev. Vet. Med. 29:9-19. https://doi.org/10.1016/S0167 -5877(96)01061-6.

Windeyer, M. C., K. E. Leslie, S. M. Godden, D. C. Hodgins, K. D. Lissemore, and S. J. LeBlanc. 2014. Factors associated with morbidity, mortality, and growth of dairy heifer calves up to 3 months of age. Prev. Vet. Med. 113:231-240. https://doi.org/10.1016/j .prevetmed.2013.10.019.

Zhou, Y., and J. J. McArdle. 2015. Rationale and applications of survival tree and survival ensemble methods. Psychometrika 80:811833. https://doi.org/10.1007/s11336-014-9413-1.

\section{ORCIDS}

Gabriel M. Dallago @ https://orcid.org/0000-0002-5725-0815

Kevin M. Wade ๑ https://orcid.org/0000-0003-0755-5917

René Lacroix @ \ttps://orcid.org/0000-0002-8618-022X

Elsa Vasseur $\odot$ https://orcid.org/0000-0002-5087-6508 